\title{
A CRISE DO LAZER MODERNO E CONCEPÇÕES DE CORPO
}

Recebidoem: 18/06/2009

Aceito em: 13/10/2009

Heloisa Turini Bruhns ${ }^{1}$

Universidade Estadual de Campinas (UNICAMP)

Campinas - São Paulo - Brasil

RESUMO: Enfoque do lazer, suas afirmações e contradições presentes na "crise da modernidade" onde três elementos mostram-se fortemente envolvidos: o trabalho como realização de si, a política como expressão da vida social (gerando um poder agressivo) e a fé no futuro como motor do projeto individual e social. Panorama este onde foi desenvolvida uma tentativa (bem sucedida) de domesticação das massas, do assentamento no trabalho e no destino à residência. Nesse âmbito, onde o aspecto racional foi privilegiado, acentuaram-se concepções de corpo onde a emoção foi desprezada, clamando por um corpo emergente, transgressivo nos seus propósitos e ações.

PALAVRAS-CHAVE: Atividades de Lazer. Satisfação no Emprego. Emoções Manifestas.

\section{THE CRISIS OF MODERN LEISURE AND BODY CONCEPTIONS}

ABSTRACT: This essay searches an approaching about leisure, its statements and contradictions present in the "modernity crisis" in which three elements are involved: work as self realization, politics as expression of social life (creating an aggressive power) as well as faith in the future as motor of social and individual project. In this panorama was developed mass domestication attempts (well succeeded), settlement down in work and residence as destiny. In this scope, rational aspects got privileges and body emotional conceptions were despised, claiming for an emergent body, transgressor in their actions and purposes.

KEYWORDS: Leisure Activities. Job Satisfaction. Expressed Emotion

\footnotetext{
1 Professora Titular da Unicamp, atual pesquisadora colaboradora do programa de Pós-Graduação em Geografia -IG / Unicamp.
} 


\section{Iniciando}

Inicio enfatizando como marco significativo o movimento ambientalista e os movimentos contraculturais da década de 1960, constituindo e desembocando em crises deflagradas no âmbito das instituições (família, ensino, Igreja, dentre outras), bem como contestando instrumentos socioculturais e político-econômicos de organização das sociedades, questionando teorias e práticas em torno da luta pelo poder. Nessa "crise" noto uma alavanca importante para o desenvolvimento dos estudos do lazer.

O lazer moderno desembocou numa contradição entre promessas e realizações associadas ao discurso do prazer e liberdade, bem como a um isolamento artificial em relação à vida como um todo. Ocorreu uma desestabilização das imagens de liberdade, escolha e satisfação de vida, as quais tropeçaram em riscos e contingências não imaginadas pela modernidade ${ }^{2}$. Daí o lazer se torna um problema dentre tantos outros. Se houve uma tentativa em remediar esse problema (promovendo e utilizando categorias fundantes e estabilizadoras como 'autodeterminação' e 'autorealização' na tentativa de 'fixar' o lazer como 'reino encantado'), o propósito deveria ser considerar o remédio como problema.

O que estou denominado de "crise do lazer moderno" deve ser compreendido na inserção das crises engendradas no próprio bojo da modernidade

\footnotetext{
2 PETERS (2000), estabelece como referência da modernidade a época que se segue ao período medieval cuja acepção histórica e filosófica toma como referência o pensamento de Francis Bacon na Inglaterra e o de René Descartes na França. Por conseqüência, porém não na seqüência, a pós- modernidade seria uma linha de pensamento questionando as noções clássicas de verdade, razão, identidade e objetividade, a idéia de progresso ou emancipação universal, os sistemas únicos, as grandes narrativas. Enxerga o mundo como contingente, gratuito, diverso, instável, imprevisível, um conjunto de interpretações desunificadas gerando certo ceticismo em relação à objetividade da verdade, da história e das normas, em relação às idiossincrasias e a coerência de identidades. Essa maneira de interpretar relaciona-se às mudanças históricas do capitalismo, ou seja, o mundo efêmero e descentralizado da tecnologia, do consumismo e da indústria cultural, no qual as indústrias de serviços, finanças e informação triunfam sobre a produção tradicional, e a política clássica de classes cede espaço a uma série difusa de "políticas de identidade" (EAGLETON,1998).
} 
como, por exemplo, a crise da "idéia de progresso" na qual estava presente a possibilidade do domínio progressivo dos homens sobre as condições ambientais de sua existência. Modelo de crescimento que mais excluiu do que incluiu, destruindo os recursos por seu excessivo consumo, não concretizando as promessas efetuadas.

Outra crise engendrada no contexto moderno refere-se à "idéia de sujeito" relacionada a um 'eu' universal, estável, unificado, totalizado e totalizante, interiorizado e individualizado ${ }^{3}$. Como discute Hall (2003), o deslocamento da concepção moderna de sujeito provocou a desestabilização da identidade, revelando o surgimento de novas identidades e fragmentando o sujeito moderno, o qual passa a ser concebido como um conjunto de 'quase-eus' conflitantes, um conjunto incerto de experiências.

Para auxiliar na discussão, utilizarei como suporte as obras de Chris Rojek "Ways of scape: Modern transformations in leisure and travel (1993)" e "Descentring leisure: Rethinking leisure (1995)". Seus trabalhos revelam um assinalável esforço de renovação teórica nos estudos do lazer, abrindo novos caminhos para a interpretação sociológica e para a reflexão sobre esse conturbado fenômeno social.

\section{A dissolução do "reino encantado"}

Nestes dois livros, Rojek tece uma crítica sistemática à tradição teórica que ele próprio designa por sociologia formalista do lazer a qual isolou os comportamentos e práticas de ocupação do denominado "tempo livre" dos contextos sócio-culturais mais amplos que estão inseridos. A crítica de Rojek incide, sobretudo, na concepção de lazer que essa sociologia professa: a idéia de que, por ocasião a outras esferas da vida social

\footnotetext{
${ }^{3}$ Essa crise está associada às frágeis certezas das generalizações as quais exigiam coerência ("ser uma mulher"; "ser um homem", dentre outras) e representações de classe e gênero pré-programavam consciências individuais (como mulheres deveriam se comportar no lazer, p.ex.) e foram largamente institucionalizadas a partir da segunda metade do século XIX (LAERMANS, 1992).
} 
(essencialmente o trabalho), o lazer é a esfera da autodeterminação individual, em que os indivíduos podem, de forma voluntária, desinteressada e espontânea exercer a capacidade de livre escolha e encontrar modos de auto-realização e autoformação à margem dos constrangimentos que a sociedade habitualmente lhes impõe. Sabemos que a disponibilidade de tempo é sempre arbitrária dependendo dos valores que atribuímos ao mesmo, além dos elementos materiais envolvidos.

Indo além, aponta como essa sociologia não apresentou propostas de mudança para quebrar a departamentalização, propor modos diferentes de vida, desconstruir os "reinos encantados" do lazer. Defensora dos fatos, da objetividade e da ciência, tornou-se cúmplice das estruturas de poder que produzem desigualdades no lazer e na sociedade.

Demarcando-se destas interpretações, que, no seu dualismo, identificam equivocadamente os "tempos" de lazer como "tempos da liberdade individual" e os isolam analiticamente das outras dimensões da vida social, Rojek desenvolve a sua reflexão em torno de três argumentos principais. Primeiro analisando esse isolamento do nexo trabalho-lazer do contexto geral das relações sociais. Em segundo lugar, o autor argumenta que as relações de lazer, sendo socialmente reguladas, põem em jogo complexos processos de luta, conflito e tensão entre interesses e concepções divergentes no que se refere à organização dos espaços e dos "tempos" de lazer, à codificação dos comportamentos, à definição dos limites de permissividade, socialmente aceitáveis nas condutas individuais. Em terceiro lugar, aponta a dependência excessiva de métodos de sondagem e dados quantitativos. Os métodos de sondagem partem de perguntas e opções de respostas estabelecidas aos participantes. 
O autor parte da afirmativa sobre um suposto imaginário da evasão e do escapismo estar associado às experiências de lazer onde um elemento de fantasia (a magia da distância) é um denominador comum nas atividades de lazer e como o lazer se alimenta da transitoriedade e do sentimento de insatisfação que caracteriza a sociedade moderna, transformando-se na contemporaneidade em uma atividade desorganizada e desregulamentada, de acordo com os conceitos de capitalismo desorganizado e de desdiferenciação desenvolvidos, entre outros, por Lasch $(1997)^{4}$, Urry $(1996,2001)$ e Lasch e Urry (1987). O lazer contemporâneo é definido através de traços como o caráter efêmero, caótico e contraditório; a sua natureza de permanente mobilidade sujeita à inovação e à moda; a relação com o consumo, com a simulação e com as imagens; o modo como desafia as fronteiras e as hierarquias culturais historicamente estabelecidas.

As preocupações do autor orientam-se essencialmente para a compreensão do modo como se organizam e ganham um sentido, as relações de lazer no contexto de duas formações sócio-econômicas e sócio-culturais determinadas: o capitalismo e a modernidade.

Trabalha num nível discursivo do lazer, o qual tem sido negligenciado pelos pesquisadores da área e toma autores bastante significativos como Derrida e De Man os quais sustentam que o sentido da realidade é estruturado pela linguagem e muitas vezes o que se toma como verdadeiro e objetivo é meramente um efeito de linguagem. Nas obras de Derrida e De Man, como argumenta, a descentralização é usada para minar as categorias de ordem e autoridade que constituem as pedras angulares da modernidade.

Rojek irá debater como a atribuição da liberdade ao lazer carrega consigo algum traço de falta de liberdade e proibição. Daí talvez, o sentimento de restrição ou

\footnotetext{
${ }^{4}$ Ver principalmente o capítulo "A reflexividade e seus duplos:estrutura, estética, comunidade".
} 
confinamento freqüentemente acompanhando nossa experiência no tempo "livre". Portanto, o lazer deveria ser considerado como parte do maquinário representacional e simbólico que nós utilizamos para negociar a vida cotidiana.

$\mathrm{Na}$ ótica da descentralização, devemos buscar sentidos e respostas ao lazer no universo representacional e simbólico da linguagem e não no mundo dos interesses "reais" e leis "efetivas".

O termo "descentramento" é utilizado na tentativa de evitar os enfoques centrados no conceito do lazer como "satisfação de vida", "prazer", "fuga" dentre outros. O termo é usado para sugerir que qualquer compreensão precisa do termo não deveria começar pelo objeto central a que nos referimos (aquele que tomamos como o objeto-em-si), mas sim pelo contexto no qual o objeto-em-si torna-se um "objeto", “uma questão", "um problema". Para o autor, o lazer está sempre relacionado à cultura e quanto mais se questiona o que é lazer, maior é a nossa compreensão do papel que exercem as normas, distinções e conflitos culturais como também da compreensão do que acontece.

O termo também é utilizado para apontar os diferentes sentidos atribuídos ao lazer por diferentes culturas. Enquanto que no capitalismo e na modernidade havia uma forte tendência de associar o lazer à "experiência real", liberação, na contemporaneidade há um interesse maior em explorar a descentralização destas associações e dos significados da idéia de lazer.

A identificação modernista de fuga, prazer e relaxamento com o lazer pode ser uma forma alternativa de regulação moral, com a conseqüência que, na modernidade, nunca tivemos certeza se éramos suficientemente livres ou suficientemente distantes daquilo de que queríamos fugir em nosso lazer. Em outras 
palavras, o autor sugere que até mesmo no auge da modernidade havia certa ambigüidade no que se refere à experiência de lazer. Em seu nível mais básico essa ambigüidade refere-se ao antigo conflito entre agência e estrutura. Ao desenvolver atividades variadas visando à liberdade, damo-nos conta de que nosso conceito de liberdade é em si mesmo, construído socialmente, e, portanto, contém suas próprias restrições e limites.

Após os movimentos sociais de liberação da década de 1960, manifestações da subjetividade atreladas à expressão do desejo, revelaram-se como direito de todos, algo buscado, não apenas no lazer e nas relações amorosas, mas também no trabalho e em todas as relações sociais. Uma participação social ganha vulto, orientada para pequenos objetivos, pragmáticos e/ou personalizados, centrada num localismo cotidiano (esportes, feminismo, macrobiótica, sexualismos, dentre outros).

Essa década revelou forte valorização da sociabilidade denotada nos movimentos sociais que eclodiram e no valor imputado às relações igualitárias entendidas como oposição a englobamentos ou hierarquizações constrangendo a manifestação dos sujeitos. O ideário da época insistiu na ausência de normas que pudessem legitimamente impor-se ao jogo do desejo exacerbando as diferenças individuais. Prevaleceu uma postura assumida pelo sujeito em relação ao 'pessoal', à ‘subjetividade', no culto das 'satisfações privadas' e pela exploração de um 'eu' ignorado no contexto ideológico de uma 'integração’ naquilo que esta possa negar ou comprometer a individualidade. Assim houve uma afirmação da busca por relações igualitárias dentro dos grupos de pertencimento e ao mesmo tempo uma valorização extrema de suas desigualdades 'internas' (SALEM,1991). 
Nesse cenário, é identificado um campo privilegiado, como mostra Sant'Anna (1993, p. 243), para o estudo da constituição do homem enquanto sujeito de si, da produção da subjetividade enquanto processo ao mesmo tempo cultural e político, transformando-se no curso do tempo e variando de acordo com as sociedades.

A manutenção de um mesmo perfil subjetivo passa não mais ser sinônimo de eficiência e de autenticidade, surgindo "identidades inconstantes" atreladas a uma “cultura da diferença". Enquanto o social, num momento histórico precedente, repousava na associação racional de indivíduos com uma identidade precisa e existência autônoma, agora surge uma "socialidade" (MAFFESOLI,1998, p.135), fundamentada na ambigüidade fundante da estruturação simbólica.

Desde o final dos anos 1960 organizações como família, classe, partido, igreja vem sendo desafiadas pelas denominadas políticas de identidade devido a sua abstração, descontextualização e ineficácia. A política de identidade se concentra em questões particulares, reconhece a inevitabilidade da diferença e da heterogeneidade e desconfiam dos discursos políticos girando em torno de imagens do universal e da massa, visualizando virtudes na flexibilidade, na mobilidade e em novas formas de fazer política.

Nas últimas três décadas, os movimentos e as lutas políticas mais importantes tanto nos países centrais, como nos periféricos e semiperiféricos foram protagonizados por grupos sociais compostos por identidades não diretamente classistas, como estudantes, mulheres, grupos étnicos e religiosos, grupos pacifistas, grupos ecológicos (SANTOS, 2003).

Cresceu um âmbito propício para o desenvolvimento de abordagens, temas e problemas até então considerados irrelevantes para a investigação social. Não mais se 
atendo à narrativa das conquistas dos "grandes homens", esses temas expandiram-se para aspectos da vida cotidiana, examinando modos de amar, trabalhar, divertirem-se, práticas e representações sociais. Os estudos do lazer avançam nesse panorama problematizando, por exemplo, questões como "tempo livre".

Na confusão entre a "idéia de lazer" com a de "tempo livre" ou na tentativa de igualá-los (o que corresponde à igualação de um conceito qualitativo a um conceito quantitativo), tendemos sempre a considerar o lazer como sendo oposto ao trabalho e assim sendo, como algo não produtivo que emperra ou debilita a produção. Nessa perspectiva, o lazer desempenha com o trabalho, como aponta Baudrillard (1992, p.179), "uma segunda cadeia de tempo", não considerando o todo como um processo construído na ambivalência e contaminação de diversos elementos (sério e frívolo; razão e emoção, vivido e refletido) experimentados na sua reversibilidade constante, sem fixação de hierarquias.

Desenvolvi essas questões no artigo "Explorando o lazer contemporâneo: Entre a razão e a emoção ${ }^{5 "}$ onde exponho as influências das idéias de Sebastian de Grazia $(1966)^{6}$ as quais foram marco de ruptura nas minhas concepções de lazer enquanto tempo residual e/ou espaço especializado e determinado.

No enfoque do tempo residual, o lazer apresenta-se como um repouso imposto pela racionalização do tempo atrelado a uma concepção de tempo como produtividade, rentabilidade e lucro. Despreza constrangimentos em relação a indeterminações, errâncias, desacertos, imaginário, emoção, prazer dos sentidos, ou seja, parâmetros não-racionais onde possibilidades despontam e não estão atrelados a

\footnotetext{
${ }^{5}$ Publicado na Revista Movimento em 2004.

${ }^{6}$ Anteriormente por mim exploradas em artigos e capítulos de livros, principalmente no capítulo "De Grazia e o lazer como isenção de obrigações" no livro "Lazer e Ciências sociais, 2002".
} 
uma matriz única, esta adotando esquematismos, enfoques descritivos e mecânicos, classificações, moldes, empobrecendo a complexidade social.

A ênfase nos parâmetros racionais desprezando os parâmetros nãoracionais (sonhos, desejos, emoções) desprezou componentes identificadores do humano e daquilo que faz a vida em movimento. Essa discussão nos remete a uma noção de sociedade, não apenas como um sistema mecânico de relações político-econômicas ou sociais, mas como um conjunto de relações interativas, composto de afetos e emoções, lembrando Maffesoli (1996, p.73).

A modernidade considera três pilares como expressivos e reguladores da sociedade: o trabalho como realização de si, a política institucionalizada como expressão da vida social e a fé no futuro como motor do projeto individual e social.

A modernidade pode ser considerada como um movimento baseado na crença em relação ao novo, descartando o velho, o clássico, o tradicional bem como no avanço do conhecimento, desenvolvido a partir da experiência e por meio do método científico. Seu significado não é fixo ou estável, mudando historicamente como resultado de um discurso teórico não esgotado onde novos significados e interpretações podem surgir.

A modernidade tentou controlar a sociedade e a natureza. As pré-condições para o sucesso envolviam a priorização do interesse individual sobre o interesse coletivo, promovendo o espírito de competição e a autodisciplina. Muitos delataram que a ordem sustentada pelas instituições da modernidade ("direitos iguais para todos", "liberdade do individual") limitava algumas capacidades humanas, pois reduziam os sujeitos ao mínimo denominador comum, ignorando as características convulsivas e vibrantes que identificam os processos de mudança na sociedade. Outros justificavam 
essas limitações em troca da segurança adquirida e os mecanismos de regulação eram apontados como criadores de condições para a liberdade e o crescimento econômico, garantindo a estabilidade e a previsibilidade. A segunda justificativa prevaleceu.

\section{O corpo emergente}

De acordo com Rojek (1995) a modernidade na sua fase primeira pode ser encarada como uma grade imposta à vida. Tanto o tempo como o espaço foi instruído segundo uma rígida disciplina e ordem, com tempos especiais para trabalho, tempos especiais para jogar; espaço reservado para atividades "sérias", espaços reservados para aspectos considerados menos "sérios" da vida geralmente relacionados ao tempo do lazer. Isso foi atingido através de um contrato "voluntário".

Trazendo Santos (2002, p. 76), nessa discussão, este nos mostra uma tentativa de colonização do prazer na modernidade ocidental através da industrialização do lazer e dos tempos "livres", das indústrias culturais e da ideologia e prática do consumismo. Porém, fora do alcance da colonização, manteve-se a irredutível individualidade intersubjetiva do homo ludens, daquele prazer que resiste ao enclausuramento e difunde o jogo entre os seres humanos.

Uma contradição é gerada nesse processo, pois as explorações dos sentidos e dos sentimentos entram em choque com um sistema baseado no cálculo quantitativo e na estandartização. A reivindicação do livre jogo da imaginação e da criatividade colide com uma realidade calcada na mecanização e insipidez. Essa é a regra, mas devemos nos basear nas exceções, pois elas podem indicar alternativas e espaços diferenciados para o exercício das novas sensibilidades contrariando os preceitos do racionalismo, na sua perspectiva empirista e materialista. 
Damásio (2000) expõe como durante a maior parte do século XX, a emoção não teve espaço nos laboratórios, pois carregava a insígnia do excesso de subjetividade, sendo colocada no pólo oposto da razão, esta última considerada a mais refinada das capacidades humanas, onde se presumia sua total independência da emoção. Não só a emoção, mas seu estudo, como coloca, provavelmente não eram racionais. A relação corpo e mente sempre foi até recentemente, uma questão tratada no âmbito da filosofia. Na última década do século XX foi colocada na agenda científica relacionada à investigação da consciência.

A partir dessas colocações podemos concluir sobre nossa modernidade ter sido caracterizada sob uma pretensa exclusividade do intelecto prevalecendo sobre as formas sensíveis do saber.

O processo histórico da ênfase no racional privilegiou um corpo na sua aparência, avaliado através do delineamento muscular, formas, constituição ósteoarticular, desprezando parâmetros não-racionais como desejos, sentimentos e emoções. Neste sentido, Alves (2005, p. 50) traz uma visão esclarecedora quando afirma não ser o corpo apenas formado por músculos e quando se fala em educação física chega-nos a imagem de um atleta com short, camiseta e tênis, pronto para alguma atividade que envolva o trabalho muscular. Porém os olhos, boca, o nariz, a pele são igualmente parte do físico, podendo atrofiar-se como se atrofiam os músculos. A inércia provocando o atrofiamento pode resultar em várias doenças, porém um corpo de sentidos atrofiados gera uma terrível doença denominada "tédio".

Os novos estudos do corpo propõem a construção de uma história, onde vida e pensamento se conectam de forma turbulenta e não linear. Para exemplificar trago as considerações de Greiner (2005), sobre a obra de Michel Feher (1989), onde são 
propostos três eixos de análise. O primeiro enfoca a relação do divino e o corpo em culturas diferentes, estudando a relação entre o homem e outras espécies vivas e abordando a diferença entre o que torna um ser animado ou inanimado, a partir de temas como autômatos, robôs e marionetes. O segundo explora os sentidos do dentro e do fora e o foco incide na elaboração das emoções, do erótico e de seus modos de expressão. O terceiro trabalha a clássica distinção entre órgão e função analisando o uso de partes e substâncias corporais como metáforas ou modelos de funcionamento da sociedade e do universo. Essa proposta de investigação envolve o aspecto ideológico das coisas, do corpo fragmentado e das situações.

O novo corpo ou o "corpo emergente" traz aspectos relacionados à sua inserção no momento contemporâneo. Ele é anarquista, não orgânico, acefálico e vital, como esclarece Greiner (2005), a partir da leitura de Derrida (1979). Tendo em vista esses parâmetros, uma mudança radical se desencadeia cujo foco localiza-se nas fissuras, nas fendas, nos entremeios e não nas partes organizadas de um todo monolítico.

O corpo emergente, descentrado, não-limitado, sistema recebendo signos, aberto para ser (re) construído através de um jogo de forças, aproxima-se da noção ‘corpo sem órgãos’ desenvolvidos por Deleuze e Guattari (1996), o qual é povoado por sensações sem ordenamento. Ele não é uma noção ou um conceito, mas uma prática, uma série de práticas. Mais do que perguntar 'o que é um corpo', 'o que um corpo significa' ou 'o que um corpo suporta', deveria ser perguntado 'o que um corpo faz'.

O 'corpo emergente' pode ser útil como recurso, no sentido metafórico, para a compreensão do que estou denominando 'crise do lazer moderno' pois traduz 
inquietações, anseios, mobilidades, apontando para a necessidade de melhor compreensão da questão bem como para a necessidade de novos enfoques.

O recurso metafórico do 'corpo emergente' traz personagens intersticiais entre a ordem e a desordem como o boêmio e o hippie nos quais está incluída a privação na busca de seus prazeres e a renúncia ao luxo, uma vez que a garantia desse implica na ameaça ao estilo de vida deles. Também o flâneur o qual Featherstone (2000, p.192), explora a partir dos escritos de Walter Benjamin (1973). Personagem composto por um lado pelo preguiçoso ou pelo desperdiçador, e por outro, pelo observador ou o investigador; uma pessoa suspeita sempre olhando, analisando, "fazendo pesquisas no asfalto", buscando uma imersão nas sensações da cidade e desenvolvendo uma sensibilidade estética nas oscilações entre envolvimento e distanciamento, entre imersão emocional e descontrole.

Esse personagem era importante para Benjamin (1973), pois apontava para a posição central da locomoção da vida social, uma vez sendo constantemente invadido por ondas de experiências novas, tanto quanto desenvolvia novas percepções ao cruzar a paisagem urbana e as multidões. Falar do flâneur, portanto, levanta uma série de questões sobre a natureza da vida pública, como também sobre a relação entre a experiência estética dos espaços públicos e as possibilidades que esses mesmos espaços apresentam para a cidadania. Esse personagem busca uma imersão nas sensações da cidade para "banhar-se na multidão", perder-se nas sensações e sucumbir ao ritmo arrastado dos desejos aleatórios, entregando-se ao jogo dos fluxos precognitivos de impressões, associações e lembranças informais. Revigorando a imaginação, pode aguçar os sentidos e estimular uma reação sensual com os fenômenos ao redor. 


\section{Buscando sínteses para encerrar}

A título de encerramento provisório nesse debate, retomo algumas questões centrais da discussão no sentido de apontar possibilidades de aprofundamento no assunto. Assim sendo, irei finalizar trazendo alguns temas os quais poderiam ser desenvolvidos numa proposta mais densa, buscando outras conexões e outros autores para o diálogo. Dessa forma ficam algumas sugestões:

- Explorar o conceito modernista de lazer como categoria limitada de prática e de experiência, onde o "lazer seguro" manifesta-se como prática ordenada e decente num espaço regrado, disciplinado e orientado, na tentativa de organizar a vida social.

- Aprofundar as relações estabelecidas com os códigos determinantes envolvidos na experiência do lazer moderno: liberdade, escolha, autodeterminação, escape e satisfação ou prazer. Aqui dois mitos manifestam-se e merecem atenção especial: o mito do prazer e o mito da liberdade. Igualmente deve ser enfocada a indústria do lazer modernista a qual corriqueiramente fabrica signos de fuga e de realização como parte de suas estratégias de marketing

-Explorar a presença da "visão donatária do lazer", ou seja, aquela que o considera como algo a ser dado ao indivíduo e à sociedade como recompensa (quase sempre relacionada ao trabalho) ou negado como punição ou forma de controle social.

- Aprofundar o fenômeno lazer (reino encantado de auto-realização e autosatisfação) enquanto parte do mundo e dos sonhos de fuga e realização com os quais a modernidade ilumina o cotidiano. Oferece o fascínio da realização que a densidade da vida nega.

- Explorar a noção de 'corpo emergente' relacionado ao lazer como possibilidade de espaço e manifestação de oposições favoráveis ao surgimento de novas 
sensibilidades, incorporando parâmetros não-racionais e contrariando os preceitos do racionalismo na sua perspectiva empirista e racionalista. Figuras da modernidade como o flâneur e o boêmio tornam-se emblemáticas nessa discussão.

E para finalizar, insisto sempre em desenvolvermos uma leitura da vida baseada na proposta da "razão sensível” de Maffesoli (2001), ou seja, um conhecimento mais aberto, incorporando o imaginário, os sentidos, a emoção, o lúdico - parâmetros não-racionais, onde múltiplas possibilidades despontam. Conhecimento não condensado numa matriz única. Aqui está envolvida o que o autor chama de 'teoria erótica', uma comunhão com o mundo no sentido de, a partir do seu interior descrever as vibrações e uma 'sensibilidade teórica' necessária para fazer sobressair o que 'já está aí' ou simplesmente ser mais capaz de perceber. Dessa forma devemos ser 'farejadores sociais' reconhecendo o instituinte, aquilo que periodicamente (re) nasce.

\section{REFERÊNCIAS}

ALVES, Rubem . Educação dos sentidos e mais... Campinas: Verus, 2005.

BAUDRILlARD, Jean. Da Sedução. 2. ed. Campinas: Papirus, 1992.

BENJAMIN, W. Charles Baudelaire: A lyric poet in the era of high capitalism. Londres: New left books, 1973.

BRUHNS, Heloisa T. De Grazia e o lazer como isenção de obrigações. In:

Lazer e Ciências Sociais: Diálogos Pertinentes. São Paulo: Ed. Chronos, 2002.

Explorando o lazer contemporâneo: Entre a razão e a emoção. Revista Movimento, UFRGS, v. 10, n. 2, mai/ago, 2004.

DAMÁSIO, Antonio. O mistério da consciência. São Paulo: Companhia das Letras, 2000.

DE MAN, P. Blindness and Insight: Essays in the rethoric of contemporary criticism. Minneapolis: University of Minnesota Press, 1971. 
DeleuZE, G.; GUATTARI, F. Mil Platôs: Capitalismo e esquizofrenia. Rio de Janeiro: Ed.34, 1996. v.3.

DERRIDA, J. L'écriture et la différence. Paris, Seuil, 1979.

EAGLETON, Terry. As ilusões do pós-modernismo. São Paulo: Jorge Zahar Editor, 1998.

FEATHERSTONE, Mike. O flâneur, a cidade e a vida pública virtual. In: Arantes, A.A. (Org.) $O$ espaço da diferença. Campinas: Papirus, 2000.

FEHER, M. et al. Fragments for a history of the human body, part 1,2 and 3. New York: Zone Books, 1989.

GREINER, Christine. O corpo: pistas para estudos indisciplinares. São Paulo: Anna Blume, 2005.

HALL, Stuart. A identidade cultural na pós-modernidade. 7. ed. Rio de Janeiro: DP\&A, 2003.

LAERMANS, R. Leisure as making time: some sociological reflections on the paradoxical outcomes of individualization. New Routes for leisure: Atas do Congresso Mundial do lazer. Lisboa: Instituto de C. Sociais da Universidade de Lisboa, 1992.

LASH S., Giddens, A.; BECK, U. Modernização Reflexiva. São Paulo: Ed. UNESP, 1997.

LASCH, S.; URRY, J. The end of organized capitalism. Cambridge: Polity Press, 1987.

MAFFESOLI, Michel. No fundo das aparências. Petrópolis: Vozes, 1996.

O tempo das tribos. 2. ed. Rio de Janeiro: Forense universitária, 1998.

. Elogio da razão sensível. 2. ed. Rio de Janeiro: Vozes, 2001.

PETERS, Michael. Pós-estruturalismo e filosofia da diferença. Belo Horizonte: Autêntica, 2000.

ROJEK, Chris. Ways of Escape: Modern Transformations in Leisure \& Travel, Macmillan. London: Rowan \& Littlefield, Boston, 1993. 1995.

Decentring Leisure: Rethink Leisure Theory. Sage, London: Thousand Oaks,

SALEM, Tânia (1991) O ‘individualismo libertário’ no imaginário social dos anos 60 . Revista Physis, v. 1, n. 2, 1991.

SANT'ANNA, D. B. Corpo e História . Cadernos de Subjetividade, São Paulo, v.1, n.1, PUC-SP, 1993. 
SANTOS, B. S. A crítica da razão indolente. 4. ed. São Paulo: Cortez Editora, 2002.

SANTOS, Boaventura de Sousa. Pela mão de Alice: o social e o político na pósmodernidade. 9. ed. São Paulo: Cortez, 2003.

URRY, John. Transports of delight. Journal of leisure Studies ,Forest Row, England 20, 2001.

O olhar do Turista: lazer e viagens nas sociedades contemporâneas. São Paulo: SESC/Nobel, 1996.

\section{Endereço da Autora:}

Heloisa Turini Bruhns

Caixa Postal 6542

13084-970 - Campinas - SP

Endereço eletrônico: luabola@uol.com.br 